To be presented at the 31 st Annual Convention of the American Institule of Electrical Engineers, Detroit, Mich., June 23, 1914, under the auspices of the Committee on $U$ se of Electricity in Marine Work.

Copyright 1914. By A.I.E.E.

(Subject to final revision for the Transactions.)

\title{
ELECTRIC HEATING AS APPLIED TO MARINE SERVICE
}

\author{
BY C. S. MC DOWELL AND D. M. MAHOOD
}

Abstract of PaPer

Electricity is being adopted to a great extent for space heating in marine work because of the simplicity and low cost of installation, saving in weight, freedom from leaks, noises and disagreeable odors as compared to steam heat, availability for heating of individual rooms, ability of placing heaters where most efficient, portability so that storerooms and other seldom-used spaces may be readily heated when desired, easeofregulation so that individual staterooms, etc., can be maintained at any desired temperature without affecting the whole system.

A comparison of convector and radiant heaters is given, the proper use of each type is shown, and the conclusion drawn that for space heating on shipboard with metal decks and bulkheads, the convector heater is most efficient.

Curves are given showing results obtained on tests to determine the best type of heater for shipboard and desirable features of heater are indicated.

With low cost of electricity on shipboard, electric heating compares favorably in cost of maintenance with steam heating. It interferes very little with the lighting load, thus increasing the load factor, and seldom requires extra generator capacity.

E SUBJECT of this paperwas sclected because it presenteda means of placing before the Institute the advantages of electric heating, which have become more prominent in marine than in land service; and because marine service has very thoroughly taken up this subject, with the result that many installations have been made. Electric heating properly applied, fits itself well to the conditions of marine engineering, where the high quality of service and its many desirable advantages over balance what increased cost of electric power there may be.

Electric cooking, with its many advantages, included in which are the saving in time and food, improvement in quality of food, ease of installing and operation, safety and sanitation, are well known, and it seems unfortunate that the use of such appliances has been held back in this country as much as it has, and is not receiving the attention it has been getting abroad.

The gradual increase in the use of electrically heated industrial apparatus is going on, the safety, saving in time and improved 
quality of work creating a popular demand in many classes of apparatus.

Electric air heating of spaces, upon which we will go into detail in this paper, is now rapidly coming into popular demand, its advantages, properly applied, making it a worthy competitor to other methods of air heating in marine engineering. The increased cost of operation over steam heat, although high in proportionate percentage is not very great in actual dollars in view of the low cost of generation of electric power aboard ships, and is further balanced by the convenience of locating the heat source where most efficient use of it can be made, the simplicity and low first cost of installation, especially where the air space to be heated is far from the boiler or engine room, the possibility of reliable automatic control of temperature, the low cost of repairs with little attention required, and the improved quality of service with freedom from leaks, noises, disagreeable odors and the other inherent objections to steam heating systems.

In some cases in the past, electric air heating systems have been failures, but usually these have been traced down as resulting either because the apparatus installed was the wrong design or insufficient for the conditions, the conditions such that an electric air heating system should never have been selected, or the particular electric heating system installed did not suit the conditions existing. In some places a small twoor three-lamp radiant heater was installed to heat a comparatively large space, the small radiator being selected probably because of high cost of power or because of the desire for appearances rather than for performance. It should be carefully considered before electric heating is installed whether the advantages of this system will overbalance the reduced cost of operation with steam, as unsatisfactory results in some past installations have proved hard handicaps to overcome, and have prevented installations that would have been very creditable. Care should be taken in selecting the design of heater and most appropriate method of installation, rather than placing appearances first with a resultant sacrifice of results, which appears to have been the practise in some past installations. As with electric cooking and industrial apparatus, electric air heating can compete with other systems only because of its adaptability, and this must be considered and made use of or the system will be found unsuccessful.

Heat is dissipated as we know, by conduction, radiation and 
convection. In considering electricity for space heating on shipboard we encounter, as a rule, metal bulkheads and decks which are good conductors of heat and every effort should therefore be made to minimize conduction losses. The radiant and convector heaters, named from the manner in which the heat is furnished, have different conditions to meet.

The radiant heaters or electric radiators dissipate the heat principally by sending off radiant energy, raise the temperature of opaque bodies in its path, and as they respond instantly when turned on have been found adaptable where a small amount of immediate warmth and intermittent use is required, such as in rooms not in general use, and where it is not desired that the temperature of the entire room be increased. Its efficiency for space heating on shipboard depends upon the material of the bulkheads and decks. As these are as a rule metal, which is a very good conductor of heat, a large part of the radiant energy is converted into heat upon striking the bulkheads and decks, is carried by conduction through the skin of the ship to the water and lost, or carried through the bulkheads and decks to the surrounding compartments and lost so far as the individual compartments are concerned. A feature observed in the radiant heater worthy of mention is the feeling of satisfaction when sitting in front of it (absent in a convector), caused by the cheerful glow present and, as had been stated by some authorities, the additional possibility of a physiological effect caused by the radiation of the higher frequency rays of infra red such as is experienced in sun baths.

Convectors heating the air in contact with resistance units, start convection currents which increase and maintain the temperature of the whole room. In space heating, where the surrounding walls are of metal, it has been seen that radiant heaters are inefficient in heating the air, and for this same reason in convectors the radiation losses should be kept down to a minimum. As the radiation increases as a function of the temperature, the temperature of the element should be kept low. Also it is better to heat a large volume of air a few degrees than a small volume of air a proportionately greater number of degrees. The former instead of rising rapidly to the top of the room and there losing its heat through the metal deck above will spread out more and warm by convection the air of the whole room.

To indicate the division of forms of heat dissipated by the 
convector and radiant heaters the following was experimentally determined, using standard constructions:

$\begin{array}{lrr} & \text { Radiant heater } & \text { Convector heater } \\ \text { Convected heat... } & 40 \text { per cent } & 90 \text { per cent } \\ \text { Radiated heat.... } & 55 \text { per cent } & 5 \text { per cent } \\ \text { Conducted heat... } & 5 \text { per cent } & 5 \text { per cent }\end{array}$

The design of radiator appears to have settled on the glow-lamp type, although resistance wires operating at a red heat are coming into use. The location of the radiator is facing and within three or four feet from the person using it. In the standard designs of radiant heater, the glow lamp is the source of heat, and the
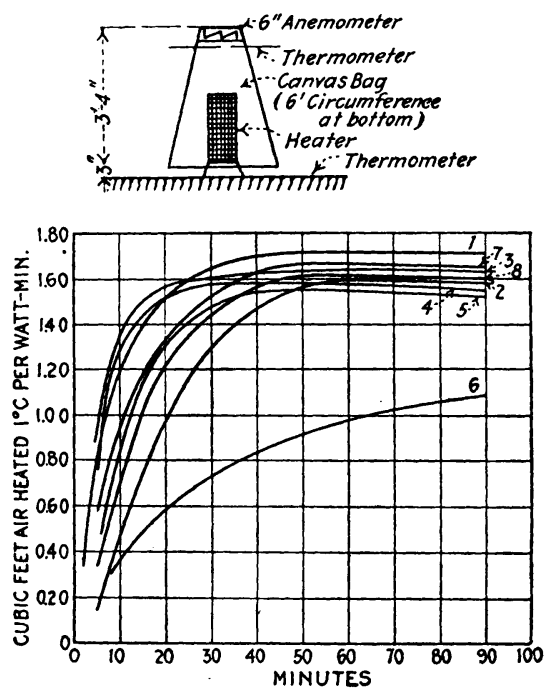

Fig. 1-Air Heated by Vertical Draft.

commercial designs include two, three and four-lamp units, the lamps being either 250 or 500 watts each, as desired.

The design of convector heaters of the various manufacturers differs principally in the details of construction of the heating units. The formation of resistance units constructed of special resistance wire or ribbon, insulated and protected in various ways, and operating as close as practicable to a tempeature best suited for the supply of convected heat, mounted in a manner to permit of efficient circulation of air, protected by a strong guard which does not restrict circulation and provided with a properly shaped deflector to give distribution of air desired, makes up this form 
of heater. Practisc has settled upon a long low heater as preferable, which design, aided by a properly shaped deflector, permits of sending the heated air out from the floor, where better mixture and uniformity of temperature is obtained without the dange $r$ of concentration of high heat at the ceiling with a greatly reduced temperature lower down. A case has been cited of poorly installed heaters where the upper berths of staterooms have been surrounded by air at such a high temperature to make it uncomfortable, whereas a glass of water placed on the floor has been close to the freezing point.



B

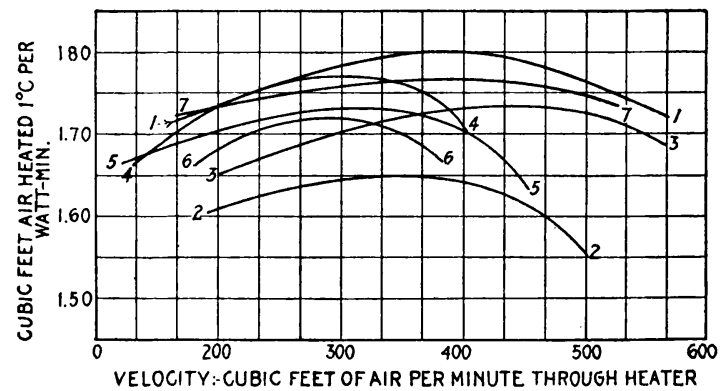

Fig. 2-Air Heated by Forced Horizontal Draft.

\begin{tabular}{ccc} 
No. & Input. & Cross-section-A-B \\
\hline 1 & 3300 watts & 169 sq. in. \\
2 & 2340 “ & 180 " \\
3 & 3000 " & 238 " \\
4 & 1760 a & 121 " \\
5 & 2240 " & 210 " \\
6 & 1220 " & 138 " \\
7 & 3250 u & 130 "
\end{tabular}

The design of the heating element is influenced greatly by the desired standard of safety to be upheld, and this has brought out designs where the vibration and jar of marine service cannot cause disarrangement and possible arcing. Insulation of the supporting feet to prevent conduction of heat to the steel deck and bulkheads is looked after during installation and need not be considered in the design of the heater. The essential requirements of convector heaters are long life, maximum heat by convection available in a comparatively short time, a construction conveniently installed, safety, good appearance, and a flexible 
design for different capacities desired in the various locations.

The operation of various designs of convector heaters is shown by the following curves obtained experimentally:

Fig. 1 shows the convected air by natural draft measured by anemometer and indicates the cubic feet of air heated one deg cent. per watt-minute. This figure also contains a sketch showing the manner in which the convected air was measured.

Fig. 2 shows the air heated by forced horizontal draft, indicating in cubic feet of air heated one deg. cent. per watt-minute, and shows the variation with velocity of the operation obtained,

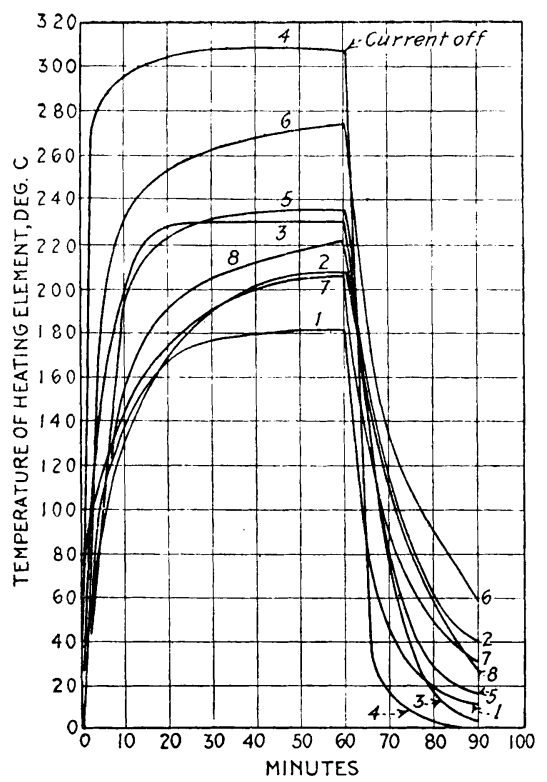

Fig. 3-Current off at End of Sixty Minutes.

and is useful in considering such heaters for indirect heating, in which the heaters are placed in the ventilating ducts.

Fig. 3 shows the temperature rise of heating elements plotted against time for the respective heaters, and is useful in judging the performance of such heaters.

Fig. 4 shows the temperature distribution taken in a room $12 \mathrm{ft}$. by $21 \mathrm{ft}$. and $17 \mathrm{ft}$. high, with and without the use of deflectors of various shapes, and using one heater. Fig. 5 shows the temperature distribution in the same room.as Fig. 4, only with the heater placed in the center of the room.

Fig. 6 shows the temperature distribution in a room $8 \mathrm{ft}$. 


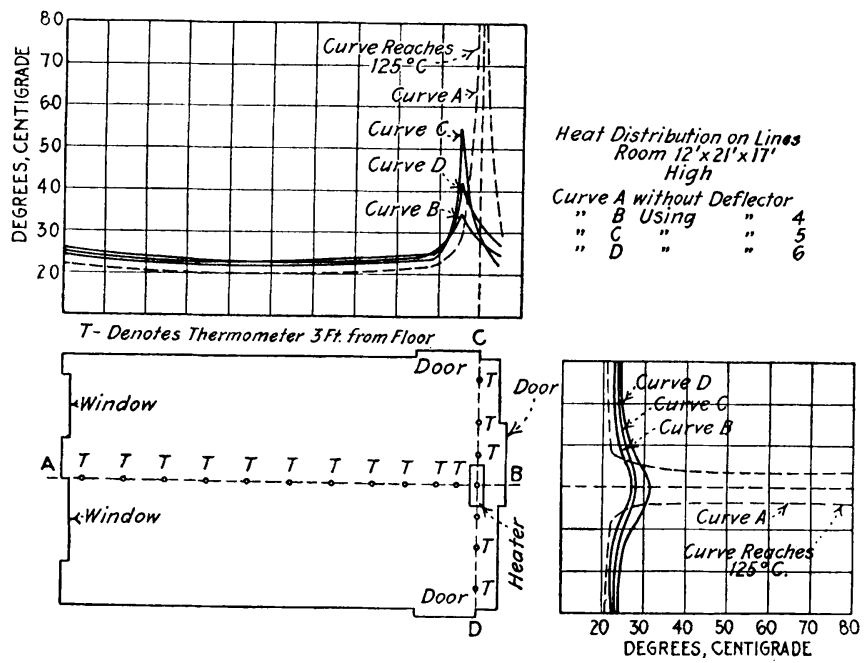

FIG. 4

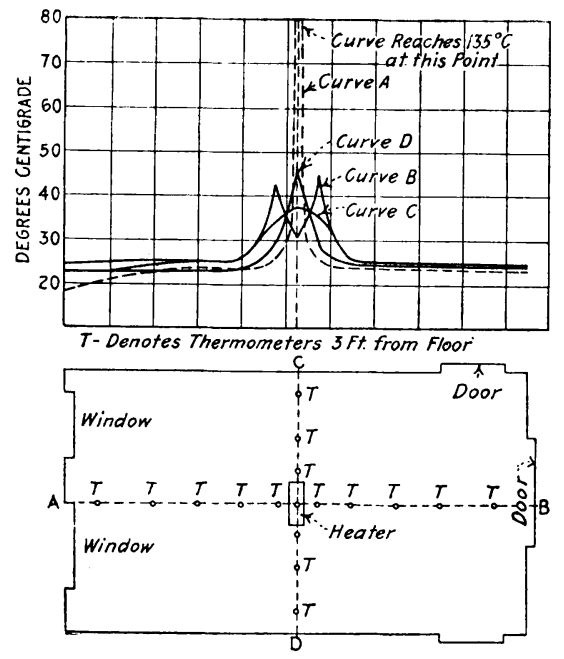

Heat Distribution on Lines $A-B$ and $C-D$

Room $12^{\prime} \times 2 I^{\prime} \times 17^{\prime}$ High

Curve A without Deflector

" $C$ C Using Deflector No.I

FIG. 5

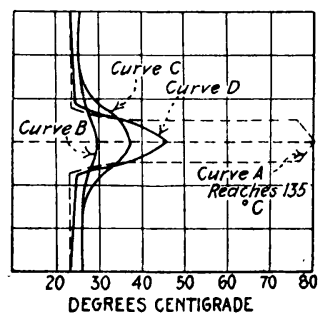


by $15 \mathrm{ft}$. and $91 / 2 \mathrm{ft}$. high with heater placed at the side of the room and using deflectors of various shapes.

Fig. 7 shows the dimensions of the living compartment in a submarine, and the results of tests of heating; and Fig. 8 shows the



FIG. 6

dimensions of inner and outer staterooms and the results of tests and heating, and Fig. 9 shows comparative rise of inner and outer staterooms using enclosed and bare resistance type heating elements.

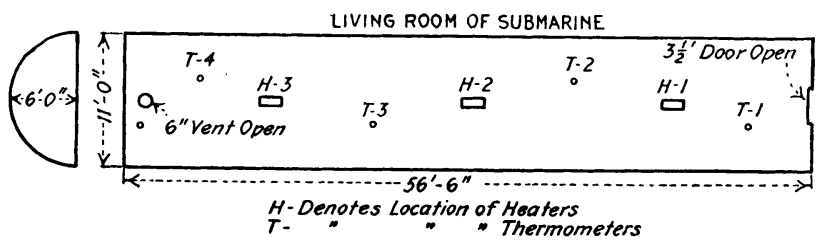

Fig. 7-Heating Tests on Submarine.

Temperatures in Centigrade

\begin{tabular}{|c|c|c|c|c|c|c|c|c|}
\hline Hour & $\begin{array}{l}\text { Total } \\
\text { watts }\end{array}$ & Outside & empe & es in & 3 & 4 & Av. & $\begin{array}{c}\text { Increase } \\
\text { above } \\
\text { outside }\end{array}$ \\
\hline $\begin{array}{l}0 \\
\text { 2nd } \\
\text { 3rd } \\
6 \text { th }\end{array}$ & $\begin{array}{l}7600 \\
7600 \\
7600 \\
7900\end{array}$ & $\begin{array}{l}8 \\
8 \\
8 \\
8\end{array}$ & $\begin{array}{l}16 \frac{1}{2} \\
18 \\
18 \\
20 \frac{1}{2}\end{array}$ & $\begin{array}{l}16 \frac{1}{2} \\
18 \\
18 \\
20 \frac{1}{2}\end{array}$ & $\begin{array}{l}17 \\
20 \\
20 \\
22\end{array}$ & $\begin{array}{l}16 \\
17 \frac{1}{2} \\
17 \frac{1}{2} \\
20\end{array}$ & $\begin{array}{l}16 \frac{1}{2} \\
18 \frac{1}{2} \\
18 \frac{1}{2} \\
20 \frac{1}{2}\end{array}$ & $\begin{array}{r}8 \frac{1}{2} \\
10 \frac{1}{2} \\
10 \frac{1}{2} \\
12 \frac{3}{4}\end{array}$ \\
\hline
\end{tabular}

Fig. 10 gives a comparison between glow and convector types of heater as regards convected heat given off, and Fig. 11 shows the types and arrangement of deflectors used in obtaining the data for the curves herewith. 
From results of tests conducted during this investigation the following general results were obtained:

(1) For each 1000 cubic feet of space, 1500 watts input is required to maintain the temperature of air space of staterooms at 70 deg. fahr., based on the heater being installed in the center of the space, having an average height of $7.5 \mathrm{ft}$., and also based on replacing the entire space of air at outside temperature of $32 \mathrm{deg}$. fahr. every quarter of an hour.

(2) Where heaters are placed as in paragraph (1), but

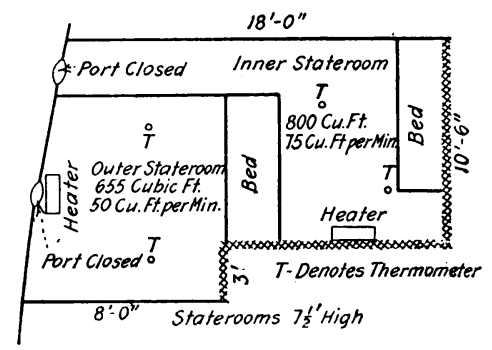

Fig. 8-Heating Tests in Staterooms.

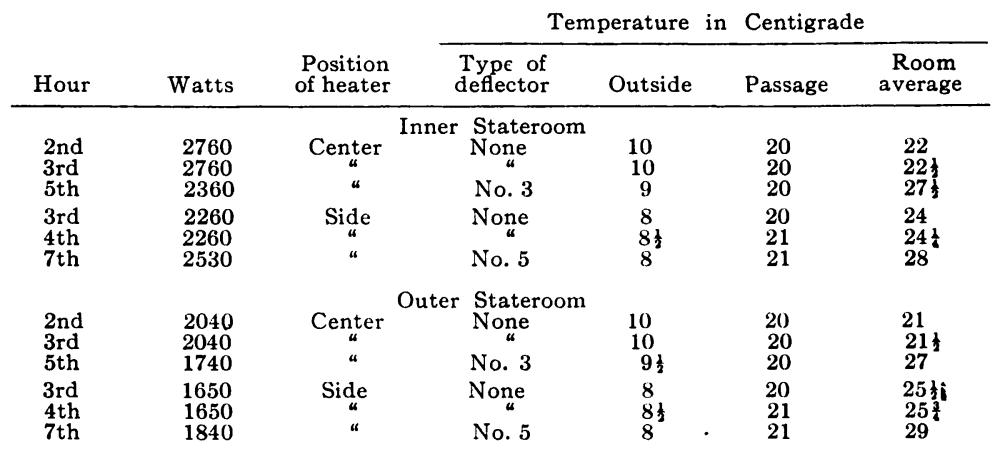

installed with deflector of design No. 2, the input should be 1200 watts for 1000 cubic feet space.

(3) Where heaters are placed close to a bulkhead, without a deflector, the input should be 1300 watts.

(4) Where heaters are placed close up to a bulkhead, and a deflector of design No. 4 is used, the input should be 1100 watts.

(5) Where the space exceeds $20 \mathrm{ft}$. in either length or width, more than one heater should be selected.

It has been brought out by Dr. Langmuir that the heat loss by convection in small wires is nearly independent of the diameter, 
and it has been found in electric convectors that with the units at the same temperature, the amount of convected heat given off per watt input, increases when the diameter of the unit is decreased. However, as the unit must be of substantial con-

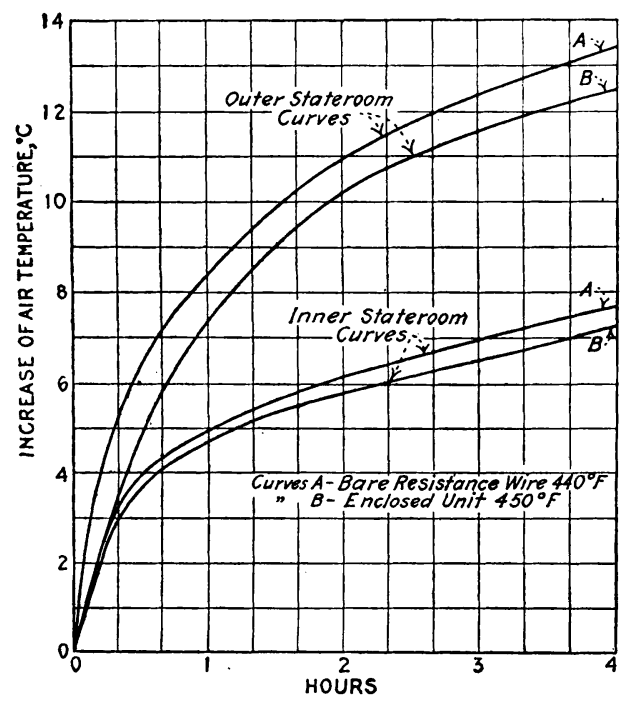

Fig. 9-Comparative Temperature Rise in Staterooms.

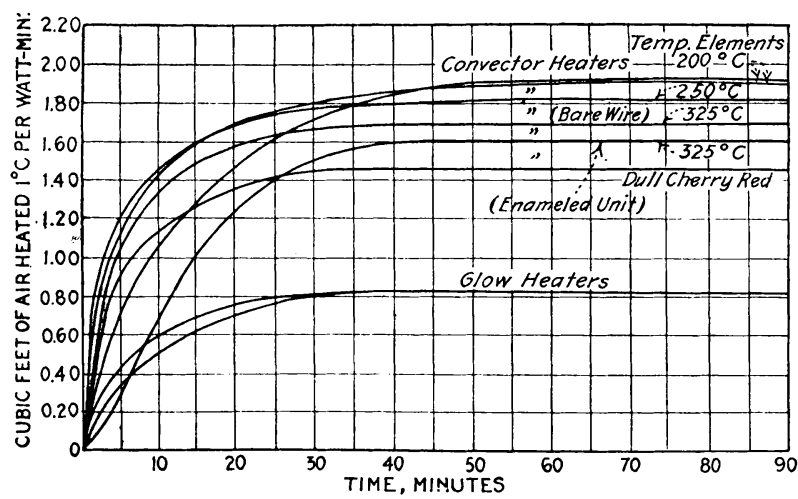

Fig. 10-Air Heated by Natural Vertical Draft-Comparison between Glow and Convector Heat.

struction, the use of small diameter units is precluded, to some extent, by other considerations.

Convectors should, where possible, be fixed in or near the center of the room, but this is, as a rule, impracticable and it becomes 
necessary to secure them near a bulkhead. The effect of their position on the heating of a room is shown in Figs. 4, 5 and 6 . When mounted near a bulkhead; the heaters should be heatinsulated fron the bulkhead and the back of the deflector should also be heat-insulated so that the losses through the walls can be kept low.

The investigation, the results of which are shown in preceding paragraphs, was conducted in order that the advantages of the best features of design and installation might be made use of to bring up the efficiency of the installation and minimize the ob-

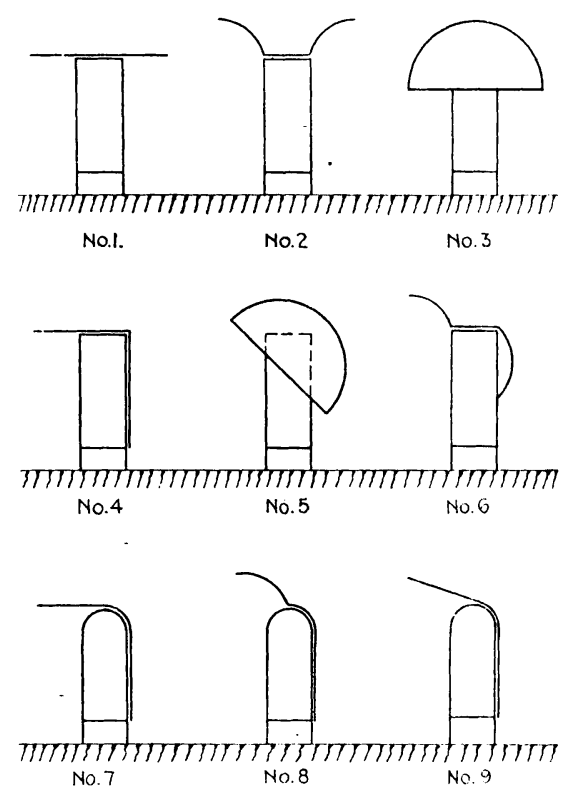

Fig. 11-Deflectors Used.

Material No. 28 B. \& S. gage sheet iron.

jection to the cost of electric air heating systems. The system of heating of spaces on shipboard which is now receiving most attention is a combination of steam and electric. Air for supply to spaces aboard ship is drawn in, by blowers from outside on the upper deck, through steam coils known as a thermotank, and delivered to the spaces at about $50 \mathrm{deg}$. fahr. In each stateroom an electric convector heater is installed by which any additional increase in temperature is available to the occupant, and such temperature may be maintained by an automatic regulator thermostat installed in the convector circuit. This very conveniently re- 
moves the difficulty existing with the steam installation with its common piping system - that of the desirability of different temperatures for occupants of adjoining staterooms-and reduces to an inappreciable amount the additional expense of electric over steam heating.

The cost of generation of electricity aboard ships having boilers already installed for propulsion is about one cent per kilowatthour and in some cases is less than this value. At such a low cost of generation, the great objections met with on land installations of electric air heating where the cost is as high as fifteen cents, do not prevail.

The adaptability of electric air heating to the extension of original installations of steam heating is obvious, and investigation shows that the installation of greater generator capacity has in most cases been found unnecessary; this being because the heating load interferes very little with the cooking and lighting loads. 